\title{
Cross-temporal and cross-national comparisons of party left-right positions
}

\author{
Michael D. McDonald ${ }^{\mathrm{a}, *}$, Silvia M. Mendes ${ }^{\mathrm{b}, 1}$, Myunghee $\operatorname{Kim}^{\mathrm{c}, 2}$ \\ ${ }^{a}$ Department of Political Science, Bartle Library Bldg, Binghamton University, Binghamton, NY 13902, USA \\ ${ }^{\mathrm{b}}$ Department of Management \& Public Administration, University of Minho, 4710 Braga, Portugal \\ ${ }^{\mathrm{c}}$ Department of Political Science, P.O. Box 1453, Southern Illinois, University Edwardsville, Edwardsville, IL 62026, USA
}

\section{Introduction}

Party left-right positions figure prominently in theories and analyses of democratic decision making. The policy meaning of elections and of the policy representation that follows requires that parties communicate along an identifiable single dimension, such as leftright, so that voters and other decision makers can know the meaning of the policy bundles parties embody. Our aim here is to investigate the possibilities and limitations when using left-right party position

\footnotetext{
* Corresponding author. Tel.: +1 607777 2946; fax: +1 607777 2675.

E-mail addresses: mdmcd@binghamton.edu (M.D. McDonald), smendes@eeg.uminho.pt (S.M. Mendes), mkim@siue.edu (M. Kim).

${ }^{1}$ Tel.: +351 253604 510; fax: +351253676 375 .

2 Tel.: +618 650 2358; fax: +618 6503509 .
}

scores from expert surveys and Comparative Manifesto Project (CMP) to compare party locations across time and across nations. Limitations, either cross-temporal or cross-national, leave gaps in one's ability to investigate how parties operate to fulfill a promise of democracy-to enable popular control over public policy. For instance, a measurement record of static party positions when in fact party position taking is dynamic, if it is, would make it impossible to investigate whether parties try to accommodate the position of the median voter (Downs, 1957; Adams, 2001), adapt their positions to one another or to their own past success (Kollman et al., 1992, 1998), follow through on their policy promises to voters while in government (Klingemann et al., 1994), or supply sufficiently dynamic offerings to electorates so as to make parties in parliament and government accurately reflect the position of 
median voters in the long run (McDonald et al., 2004). Non-comparable measurements of left-right positions across nations render doubtful the results of analyses into whether left- and right-leaning governments in different nations adopt different policies (Lijphart, 1999: pp. 258-300; McDonald and Budge, 2005).

On the question of cross-time comparisons, what we know from the outset is that left-right positions as measured by expert surveys are mostly static but for a small amount of noise (McDonald and Mendes, 2001: p. 100). What is one to make of that? One possibility is that party left-right position taking is, in fact, more static than dynamic. And, even if it are more dynamic than static, which is what expert observers assert when asked (see, e.g., country-specific commentary in Müller and Strøm, 2000), it is possible that empirical analysts will have to work with static measurements and limit their inquires to questions where party position dynamics do not matter, because expert survey measurements are the best we can do on the left-right dimension. To confront these two possibilities, we use the CMP record of party left-right positions over the post-War period to investigate whether it is plausible to infer there are systematically observable party dynamics along the leftright dimension.

On the question of cross-national comparisons, there is no doubt that expert surveys and the CMP were designed to capture these. Peter Mair and Frank Castles put the point directly when they reflected on what motivated them to carryout their survey.

What was needed, ..., was a more systematic data base, in which variations across a common crossnational scale could be compared, and in which real differences between parties could be measured (Mair and Castles, 1997: p. 151).

Whether Castles and Mair, others who pursued their expert survey approach, and still others who worked on the CMP succeeded in identified cross-nationally comparable party positions stands today more as an article of faith than as an intensively investigated and demonstrable fact. Here we investigate the success each has had in measuring left-right positions in ways that permit meaningful cross-national comparisons.

The analysis begins with a consideration of why one should care about left-right positioning and how its meaning is captured by the expert surveys of Castles and Mair (1984), Laver and Hunt (1992), and Huber and Inglehart (1995), on the one hand, and by the CMP, on the other. Our results show that expert surveys and the CMP can be used to characterize left-right party positions in similar ways and that party positions in several but not all policy domains are associated with left-right. With that as the backdrop, our second analysis proceeds to ask whether there are dynamics in the left-right party positions worth recording and taking into account. While expert surveys measure the longrun general tendencies of party left-right positions, our analysis of the CMP shows there are systematic dynamics to party left-right positions. Our third and final analysis asks whether it is plausible to think expert surveys and the CMP capture important differences across nations. These results show that expert surveys do not carry us much beyond what could be achieved by scoring party left-right positions according to each one's party-family affiliation. The CMP, on the other hand, records meaningful differences across nations.

\section{Left-right party positions}

Left-right is the core currency of political exchange in Western democracies (Huber and Inglehart, 1995). As with price and quantity in economic exchange, it is ever-present in the thinking about politics for most scholars and commentators. That is not to credit leftright with importance because it so often figures prominently in political writing and conversation. To do so is a flimsy ad populum fallacy. The serious argument runs the other way around. Left-right, or some similar singledimension concept, is fundamentally important to empirical and normative democratic theory, and therefore theorists, analysts, and commentators frequent rely on it to explain and evaluate the operation of democracies.

An important lesson to be taken from a half-century of applying social choice theory to the study of democratic politics is this: if policy meaning can be gleaned from democratic decision making, a single dimension such as left-right is required. Collective decisions that invoke several dimensions threaten to negate the possibilities of elections having policy meaning (Dahl, 1956: pp. 124-131; Epstein, 1964) and of a science of democratic politics (Riker, 1980; Ordeshook, 1980). Thus, if democratic processes are capable of creating popular control of public policy and, for political scientists, if democratic processes are going to be the subject of systematic theorizing and testing, we must accept that some forms of institutional arrangements, parties among them, control dimensionality so as to induce equilibrium expectations (Shepsle, 1979; Shepsle and Weingast, 1982). Other dimensions will come to the fore from time to time, with the effect and sometimes the purpose of upsetting equilibrium expectations (Riker, 1983, 1986), but to grasp their importance one 
209 has to start with an understanding of what otherwise 210 would happen. That will usually come from a predomi211 nant dimension such as left-right. So even in the face of 212 multi-dimensional maneuvering, left-right has a theoret213 ical role to play.

What is meant when referring to policy preferences as left and right? In contemporary politics it refers most directly to the scope and breadth of what goods and services should and should not be public goods. Those who want the government to organize a nation's economy are on the left; those who want private enterprise to organize a national economy are on the right. Advocating public ownership of industries puts one far to the left, desires to have government closely regulate privately owned firms are not quite as far left. Government control over the means of production is only part of the economic aspect. Economic distribution issues, in terms of activities that we associate with the modern welfare state, also distinguish left from right. For example, is medical care a public good? Persons and parties on the left versus right answer that question differently. It should be delivered to those who have earned enough to purchase it (right), to the elderly only (center-right), to those whose resources indicate they could not purchase it for themselves (center-left), to everyone (left). The same question could be asked about education, food, housing, clothing, etc. Being on the right means one sees little if any need for government involvement in the distribution of these goods and services; gradations of being on the left see some greater (more left) or lesser (less left) need for government involvement.

It would be wrong, however, to describe the left-right continuum entirely as a bundle of public good/economic issues that go together in predictable ways? That does not cover left-right in the 18th and 19th centuries and it does not even cover some of the meaning we have in mind today. The term left-right was around in the eighteenth and nineteenth centuries when the scope of public goods was so narrowly circumscribed that the economic policy issues that are so prevalent today played at most a small role in drawing a line of distinction between those on the left and those on the right. Furthermore, when talking about left-right in contemporary times, the notion of extreme-right parties is applied to nationalist parties with authoritarian prescriptions for social order. Whether an extreme-right party is neo-fascist in the sense that it advocates a large economic role for government, or free-marketeer in the sense of advocating little or no economic role for government, or largely silent on economic matters, extreme-right parties are easy to identify.
The idea that builds a bridge to the political discourse of the 18th and 19th centuries and that links the concept of left-right to extreme-right parties of today is the prescription for whether society ought to recognize privilege and, if so, on what basis. The left-right actors of the 18th and 19th centuries engaged in debate over whether the worth of human beings could be conditioned by one's inherited status and closeness to God. There were privileges to be enjoyed by the landed nobility and ecclesiastical hierarchy, arguably. Liberals, on the left, challenged this interpretation of the social order; conservatives, on the right, defended it. We still see remnants of the argument over privilege today. Those on the extreme right want to grant privilege based on blood lineage, whatever the privileges should becitizenship, voting rights, pensions and other forms of welfare and social services, education, etc. And one's view of privilege has expanded so that it extends to the definition and scope of public goods. Center-rightist are more inclined to see privilege as something to be earned, determined by what free-market benefits come from one's talents. Those on the left are inclined to see less need to grant privilege for any reason, other than by virtue of one's humanity.

Here we ask how similar the tale of left-right positions is when recorded by expert survey and CMP data. The three expert surveys and the CMP cover commonly 79 parties in 17 nations. ${ }^{3}$ The Castles-Mair and Huber-Inglehart surveys were expressly designed to locate parties in the left-right space. Laver-Hunt asked experts to place parties along pro-con continua in each of eight policy domains. The CMP codes policy emphasis in 56 categories and uses 26 of them to construct a leftright party score.

Fig. 1 shows the commonality in left-right party scores for the two left-right expert surveys and the CMP, as located in a factor space defined by the three left-right scores and the eight policy category scores from Laver-Hunt. Five of the eight Laver-Hunt issue categories are highly correlated with left-right, though clearly party alignments on matters of the environment, urban interests, and decentralization, which have little to say about privilege, leave room to maneuver outside of the left-right space. After extracting two dimensions (varimax rotation, with dimension extraction for eigenvalues $\geq 1.0$ ), we rotated the axes so that the first factor

\footnotetext{
3 The nations are Australia, Austria, Belgium, Canada, Denmark, Finland, France, Germany, Ireland, Italy, Netherlands, New Zealand, Norway, Spain, Sweden, United Kingdom, and United States. Data for this analysis and those reported below are available at the Binghamton University website found at the following addresshttp://www.binghamton.edu/polsci/research/mcdonalddata.htm.
} 


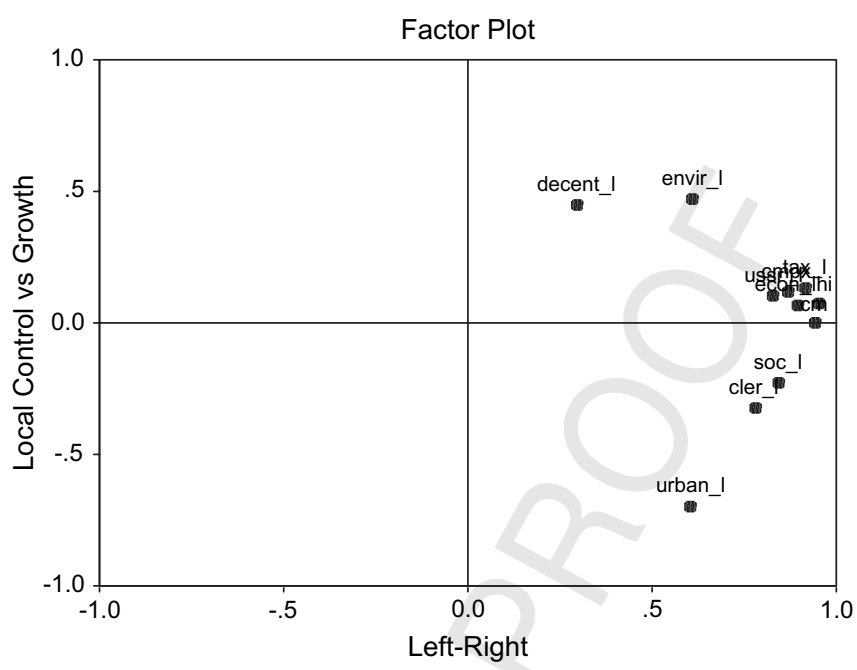

Loadings

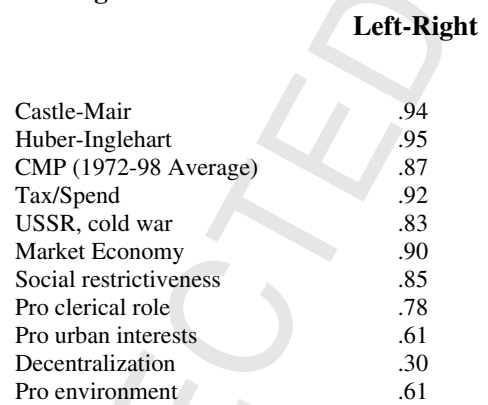

\section{Local Control \\ vs Growth}

Fig. 1. Factor analysis results party positions.

would indicate left-right as marked precisely by Castles-Mair (i.e., the Castles-Mair loading on the first factor is maximized and on the second factor is zero). Given that the Castles-Mair loading on factor 1 is 0.94 and on factor 2 at 0.00 , factor 1 is reasonably interpreted as something close to a left-right factor and nothing else. With that, each squared loading $\left(h^{2}\right)$ on factor 1 can be interpreted as a statement of the validity of each measure as an indicator of party left-right positions.

Castles-Mair and Huber-Inglehart are the two most valid measures by this methodology and its associated assumptions, with $h^{2}$ values in the vicinity of 0.9 . The CMP is a fairly valid indicator, by the standards of validity founded on the expert surveys, but about a sixth of its variance is distinctly different from that of the expert surveys-i.e., CMP squared loading, $h^{2}$, is $0.87^{2}$ or 0.76 , and $1-(0.76 / 0.90)=0.16$.

What contributes to the CMP distinctiveness? One possibility is that the CMP contains one-sixth more noise than the expert measures. Another possibility is that the specific variance (in contrast to its common variance, to use factor analysis terminology) in CMP scores accounts for something real but which is not shared by the expert scoring.

What might be the sources of real (systematic) variation in CMP scores that is not commonly shared with the expert survey scores? The two possibilities we explore below are that the CMP left-right scores contain variation associated with a degree of dynamic party position taking that expert surveys mostly miss and a degree of cross-national differentiation that expert surveys also miss.

\section{Party positions and their dynamics}

Elsewhere, McDonald and Mendes have shown that expert survey scores are highly reliable but have very little dynamic variation (McDonald and Mendes, 2001: p. 100). This is troubling because it presents us with the possibility that expert scores are operating as if they describe general left-right tendencies across time, a mean position for each party. Such fixed positions have something very appealing going for them. They appear highly reliable from one decade to the 
next; because they are measuring the same thing at different times. But this appealing reliability comes at a potentially high price: They preclude analyzing party movements, if there are real party movements.

Are the expert scores missing any important dynamic variation? We investigate that possibility by analyzing the dynamics of party left-right locations for 81 parties in 17 Western nations using the CMP data set (Budge et al., 2001). ${ }^{4}$ Except as noted for two Danish parties and with allowance for the special circumstances of Belgium, France, Italy, and the Netherlands, the 81 parties include those for which we have data on coded manifestos in consecutive elections totaling more than half of a nation's elections from the late 1940s through $1998 .{ }^{5}$ The Belgian parties split along language lines during the period $1968-77$, and we treat the preand post-splits as separate party systems. Parties during France's Fifth Republic, but not during the Fourth Republic, are included. The analysis of Italian parties stops in 1992 after which many of the Italian parties reconfigured. Finally, the three separate Christian parties in the Netherlands combined at the time of the 1977 Dutch election to form the CDA; the three parties and the CDA are treated as four separate parties.

In the factor analysis (Fig. 1), the CMP party scores were their averages over the 1972 through 1998 period. As a first step in examining dynamics we can ask how reliable post-War average party positions are given the left-right movements recorded by the CMP. The question is whether a static representation as portrayed by mean values, in the face of the over-time variation of each party's position, is a reliable characterization. It

\footnotetext{
${ }^{4}$ These are not the exact same 17 nations used in the factor analysis. Here we exclude Spain, because the number of elections since democratization is too small and we include Luxembourg, which was not present in the factor analysis because its parties had not been scored by Castles and Mair.

5 A few data points in CMP are estimated, based on a party's manifesto at an earlier election. Such carryover data present problems for our analyses on two counts. They artificially reduce variations and create autocorrelation. Therefore, we exclude carryover manifestos. The exclusion is usually for one election at the beginning or end of a party's series. The single election exclusions are the Belgian PVV in 1995, the Belgian FDF in 1965, the Belgian VU in 1958, the Canadian SC in 1972 and 1974, all Danish parties in 1998, all Norwegian parties in 1997, and the Swiss SVP in 1947. Dropping the 1998 Danish data caused observations on the Danish CD and KF to go from 11 of 22 (half) to 10 of 21 (less than half). Still, we decided to keep both Danish parties in the analyses. In the case of the French Conservatives, the entire series had to be excluded because several of its manifestos are recorded as estimates. Also, the single manifesto score of the United Socialists in Italy for the 1968 election is the 1968 score that we assign individually and separately to the PSI and PSDI.
}

is not. Regressing the observed positions onto the party mean values reveals a slope of 1.0, as required by definition. The $R^{2}$, however, is only $0.649(N=924,17$ nations times the number of parties per nation times the number of manifestos per party). That means that only about two-thirds of the systematic variance in these data is coming from differences in average party positions. The remaining one-third is noise, real movements in party positions, or some combination.

\subsection{Party left-right dynamics}

We assess whether evidence of systematic change in party positioning exists by estimating an autoregressive equation on each party's series of positions. Three different patterns could result. First, party positions that shift over the long run, such as those forming a trend, will result in an autoregressive equation that indicates a party's long-run expected value (a sort of dynamic mean) is different from its mean. ${ }^{6}$ Second, a party that changes by drifting away from its mean position for a sustained period but later coming back to it, a characteristic of cyclical movements, will result in an autoregressive equation with patterned change that leaves the long-run expected value and the mean close to one another. Third, autoregressive results indicating that the mean is a reasonable description regardless of a party's position at the previous election (i.e., the slope could reasonably be inferred to be zero) are situations where parties are moving as-if randomly around their respective mean positions, neither trending nor drifting.

To describe in more detail how the autoregressive equation can be used to identify what we label in accordance with the three patterns, respectively, as: (1) changers; (2) drifters; and (3) homeostatic wanderers, we start with the equation as applied to any one party's left-right position. It takes this form:

$\mathrm{LR}_{t}=\alpha+\beta \mathrm{LR}_{t-1}+\varepsilon_{t}$.

$\mathrm{LR}_{\mathrm{t}}$ is a party's left-right position for the current election; $\mathrm{LR}_{t-1}$ is that party's left-right position at the previous election; $\alpha$ is the intercept; $\beta$ is the slope; and $\varepsilon_{t}$ is

\footnotetext{
${ }^{6}$ As we explain immediately below, the dynamic mean we are referring to is distinguishable from the commonly referred to mean. For estimation of a dynamic mean one first estimates a bivariate autoregressive equation to determine whether the slope is zero. If the slope is zero, then the mean value of $Y$ at any given time is estimated to be equal to the autoregressive intercept. If the slope is different from zero, then the mean, which is estimated to vary, is calculated by dividing the intercept by one minus the slope. For informative discussions about autoregressive equations, with substantive applications to politics, see Spafford (1971) and Price and Sanders (1993).
} 
assumed to be a set of well behaved, homoscedastic and non-autocorrelated, errors in party positions at the current elections. When the estimated value of $\beta$ is not distinguishable from zero, it indicates that the movements around the party left-right mean are, so far as we can tell, random deviations from which a party can be expected to return to its typical (mean) position at the next election. When $\beta$ is distinguishable from zero and in the interval -1 to +1 (all of our estimates are in that interval), party movements show signs of sustained changes through time. For example, a statistically significant slope of 0.75 indicates that a deviation from the party's long-run typical left-right position is expected to move toward (but not to) that position at the next election. The speed at which it approaches that long-run typical position is $(1-\beta)$. In the case of the example, $(1-\beta)$ is $1-0.75$, or 0.25 ; therefore that party is expected to move one-quarter of the way from where it was at the last election toward where it is expected to be in the long run.

The difference between where we can expect a party to be in the long run and where it is on average is one way to describe how and by how much a party has changed. To estimate where a party's left-right position will be in the long run, we divide the intercept by the value of one minus the slope-i.e., $[\alpha /(1-\beta)]$ (see Spafford, 1971; Price and Sanders, 1993).

As we shall see, there are parties for which the slope is distinguishable from zero and the difference between the mean and the party's long-run expected position is large. These are the parties we label changers. There are also instances of parties with slopes distinguishable from zero but with small differences between its mean versus its long-run expected value. These are parties that drifted one way, then the other-going through cycles of reliably predictable and moderately sustained movements. We call these parties drifters. Finally, there are parties that diverge from and converge towards their mean values in an unpredictable manner. For these parties, movements away from their mean positions are expected to be short-lived, with an expectation of each one returning to its mean position at the next election. We call these parties homeostatic wanderers.

For a party with patterns of change that show a shift to a new position, as would be true for a party whose positions create a trend, we have said there is a large difference between its mean left-right position and its long-run expected left-right position. Fig. 2 is a histogram that displays these differences for each of the 81 parties. Not many parties show much difference. Only 10 of the 81 parties $(12.3 \%)$ have expected long-run positions that differ from their respective mean positions by more than \pm 4 points. Two of those 10 parties - the Dutch CDA and Italy's PSI-show changes larger than \pm 4 , but their changes are based on estimated slopes that we deem to be unreliable.? That leaves eight parties that changed their left-right positions through time in a reliably estimated manner. They are the eight, so-called, changers.

The eight changers are listed in Table 1. There, too, we provide a description of the pattern of change along with each party's mean value over the period, its socalled target position (which is where, based on our analysis, we expect the party left-right position to move to over the long run), and its left-right position by decade. The first thing to notice is that of the eight changers four no longer existed in the same organizational form in the late 1990s. Two Italian parties, the PSDI and PRI, each of which had been moving to the right, were themselves transformed when the party system as a whole changed after the 1992 election. In addition, two other changers are Dutch Christian parties-ARP and CHU-that combined, also with the Catholic KVP, to form the Christian Democratic Alliance (CDA) in the 1970s. The movements of both Dutch (Protestant) Christian parties show a trend leftward, and after they merged into the CDA they held a center-left position. That leaves four parties that have different left-right positions in the 1990s compared to positions they took in, say, 1960. Patterns of change for these four are consistent with what informed

\footnotetext{
${ }^{7}$ We take what could be considered a liberal approach to a decision rule for reliably estimated relationships, but what we have done in fact is to take account of the effect of measurement error. Errors in an $X$ variable reduce the magnitude of an estimated slope, and errors in both the $X$ and $Y$ variables are likely to increase the slope's standard error. Given that a $t$-ratio is $\left(b / s_{b}\right)$, the effect of measurement errors makes tests of statistical significance at conventional levels (e.g., $P<0.05)$ prone to Type II errors. Therefore, we loosen the conventional standard of, say, $P<0.05$ so that reliably predicted behavior is deemed to exist when a slope's $t$-value has a magnitude such that $t<-1.5$ or $t>1.5$. Twenty-one parties show a statistically significant relationship at conventional levels, compared to 27 using our looser $1.5 t$-value. Note that the liberal decision rule has no effect on our subsequent analyses and evaluations, except to cause us to provide detailed descriptions of change for 27 (8 changers and 19 drifters) in Tables 1 and 2, instead of 21 parties. Tests of statistical significance could also be affected by autocorrelated errors. We have checked for autocorrelation for each of the 81 party series. When a lagged value of $Y$ is on the right hand side, the test (e.g., Durbin's $h$ ) is a large sample test and is not especially powerful. With our small samples, between 6 and 21 elections for any one party, about half of the tests are not calculable. However, we can and have calculated values of rho for all parties. We find an estimated rho between \pm 0.25 for 72 of the 81 parties. Therefore, in no more than few cases could it be said that a concern about autocorrelation is warranted.
} 


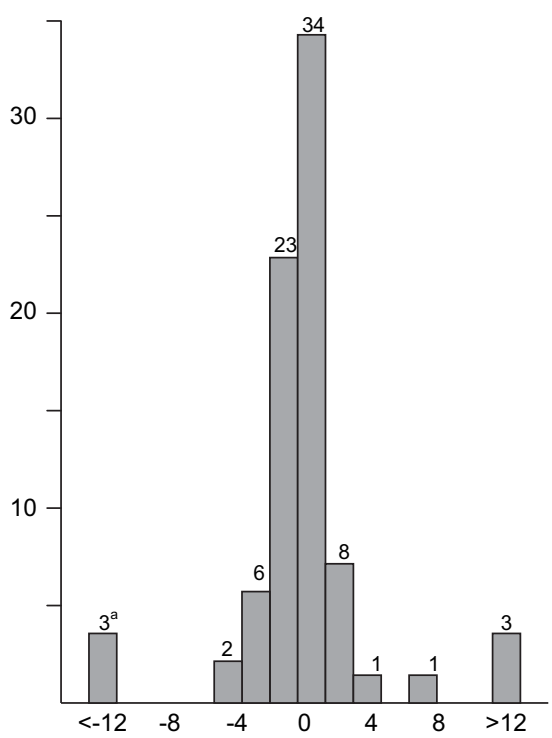

Fig. 2. Histogram of the difference between a party's mean and longrun. Expected left-right position. Source: Compiled by authors from CMP data (Budge et al., 2001). 'One large leftward changer (-34, Dutch ARP) is not fully depicted in this representation; it is one of the three cases in the category labeled $<-12$.

observers of these parties tell us was happening throughout the period. The Austrian FPÖ is reported to have placed itself to the left during the 1960s in order to gain favor with the SPÖ for government coalition bargaining purposes, then gave up that strategy and moved decidedly to the right (Müller, 2000: p. 87). Mair (1986) reports that Fine Gael took noticeable steps to the left during the 1960s and 1970s and stood clearly to the left of Fianna Fáil during that time. Hanne Marthe Narud and Kaare Strøm have said of the leftward drift of Norway's SP that "the party's opposition to European integration has gradually generalized into a greater skepticism towards market economies" (Narud and Strøm, 2000: p. 164). Finally, the Democrats in the United States, especially under the leadership of President Clinton but presaged by smaller movements toward the center during the 1980s, is generally understood to have moved to the center (see, e.g., Erikson et al., 2002).

Nineteen parties are classified as drifters, more than twice the number of changers. The drifters are listed in Table 2. Recall that our classification criterion for drifters versus changers is that, while a drifter's position undergoes predictable and sustained changes, in the long run its left-right position is not expected to be much different from its mean position over the entire period. This is reflected in the column in the middle of the table, where the mean and (long-run) target values are reported. One general pattern of drift covers the Anglo-American parties. In Australia, New Zealand, UK, and U.S., the drifters each drifted rightward, a movement that also describes the U.S. Democrats in

Table 1

Identification and description of movements by changers

\begin{tabular}{|c|c|c|c|c|c|}
\hline \multirow[t]{2}{*}{ Country } & \multirow[t]{2}{*}{ Party } & \multirow[t]{2}{*}{ CMPid } & \multirow{2}{*}{$\begin{array}{l}\text { L-R } \\
\text { Mean }\end{array}$} & \multirow{2}{*}{$\begin{array}{l}\text { L-R } \\
\text { Target }\end{array}$} & Pattern of change \\
\hline & & & & & Numerical value of L-R mean by decade \\
\hline Austria & FPÖ & 42420 & 2.5 & 14.2 & $\begin{array}{l}\text { Started center, moved left, then steadily back to center and continued on past } \\
\text { center to right }\end{array}$ \\
\hline & & & & & $50 \mathrm{~s}=+4.5 \quad 60 \mathrm{~s}=-26.8 \quad 70 \mathrm{~s}=-13.8 \quad 80 \mathrm{~s}=+4.6 \quad 90 \mathrm{~s}=+39.5$ \\
\hline Ireland & FG & 53520 & 11.1 & 6.5 & $\begin{array}{l}\text { Started right, moved steadily to center-left until } 80 \mathrm{~s} \text {, then moved to center-right } \\
50 \mathrm{~s}=+46.6 \quad 60 \mathrm{~s}=-2.0 \quad 70 \mathrm{~s}=-17.6 \quad 80 \mathrm{~s}=+2.8 \quad 90 \mathrm{~s}=+9.3\end{array}$ \\
\hline Italy & PSDI & 32330 & -12.2 & -4.5 & $\begin{array}{l}\text { Started left and moved rather steadily toward and to center } \\
50 \mathrm{~s}=-28.5 \quad 60 \mathrm{~s}=-24.1 \quad 70 \mathrm{~s}=-5.3 \quad 80 \mathrm{~s}=+3.5 \quad 90 \mathrm{~s}=+2.3\end{array}$ \\
\hline Italy & PRI & 32410 & -0.7 & 15.3 & $\begin{array}{l}\text { Started left-center and moved, in step-like manner, rather steadily to right } \\
50 \mathrm{~s}=-17.0 \quad 60 \mathrm{~s}=-10.0 \quad 70 \mathrm{~s}=-1.0 \quad 80 \mathrm{~s}=+22.8 \quad 90 \mathrm{~s}=+36.7\end{array}$ \\
\hline Netherlands & ARP & 22523 & 5.0 & -29.6 & $\begin{array}{l}\text { Steady movement from center-right to center-left when it ended in early } 70 \mathrm{~s} \\
50 \mathrm{~s}=+16.1 \quad 60 \mathrm{~s}=+1.6 \quad 70 \mathrm{~s}=-16.1 \quad 80 \mathrm{~s}=\sim \sim \sim \quad 90 \mathrm{~s}=\sim \sim \sim\end{array}$ \\
\hline Netherlands & $\mathrm{CHU}$ & 22525 & 8.9 & -3.1 & $\begin{array}{l}\text { Started right, moved to center in the } 60 \mathrm{~s} \text { and ended in center-left in the early } 70 \mathrm{~s} \\
50 \mathrm{~s}=+21.5 \quad 60 \mathrm{~s}=+4.0 \quad 70 \mathrm{~s}=-17.7 \quad 80 \mathrm{~s}=\sim \sim \sim \quad 90 \mathrm{~s}=\sim \sim \sim\end{array}$ \\
\hline Norway & SP & 12810 & -5.3 & -17.3 & $\begin{array}{l}\text { Started right-center, moved steadily and quickly left, reaching left-center by } \\
\text { mid-60s and stayed there } \\
\begin{array}{llll}50 \mathrm{~s}=+18.8 \quad 60 \mathrm{~s}=-12.7 \quad 70 \mathrm{~s}=-16.6 \quad 80 \mathrm{~s}=-15.7 & 90 \mathrm{~s}=-15.6\end{array}\end{array}$ \\
\hline U.S. & DEM & 61320 & -12.8 & -1.9 & $\begin{array}{l}\text { Started left-center into the } 1980 \text { s, then moved steadily to and through center to } \\
\text { center-right }\end{array}$ \\
\hline & & & & & $50 \mathrm{~s}=-19.1 \quad 60 \mathrm{~s}=-15.6 \quad 70 \mathrm{~s}=-20.4 \quad 80 \mathrm{~s}=-14.1 \quad 90 \mathrm{~s}=+10.5$ \\
\hline
\end{tabular}

Source: Estimations and compilations by authors based on CMP data (Budge et al., 2001). A changing party takes left-right positions in a manner that change predictably from one election to the next and show estimated long-run left-right position away from its mean left-right position over the post-war period (beyond \pm 4 points). 
Table 2

Identification and description of movements by drifters

\begin{tabular}{|c|c|c|c|c|c|}
\hline \multirow[t]{2}{*}{ Country } & \multirow[t]{2}{*}{ Party } & \multirow[t]{2}{*}{ CMPid } & \multirow{2}{*}{$\begin{array}{l}\text { L-R } \\
\text { Mean }\end{array}$} & \multirow{2}{*}{$\begin{array}{l}\text { L-R } \\
\text { Target }\end{array}$} & Pattern of drift \\
\hline & & & & & Numerical value of L-R mean by decade \\
\hline Australia & LAB & 63320 & -11.1 & -7.3 & $\begin{array}{l}\text { Started left, stayed left through the } 70 \mathrm{~s} \text {, drifted to varied positions at and around the center } \\
50 \mathrm{~s}=-22.5 \quad 60 \mathrm{~s}=-14.2 \quad 70 \mathrm{~s}=-22.1 \quad 80 \mathrm{~s}=+3.2 \quad 90 \mathrm{~s}=+5.6\end{array}$ \\
\hline Belgium & CVP & 21521 & -1.9 & 1.5 & $\begin{array}{l}\text { Started center-left in late } 60 \mathrm{~s} \text {, moved steadily to center-right in } 80 \mathrm{~s} \text {, and moved to center } \\
50 \mathrm{~s}=\sim \sim \sim \quad 60 \mathrm{~s}=-12.8 \quad 70 \mathrm{~s}=-8.2 \quad 80 \mathrm{~s}=+7.7 \quad 90 \mathrm{~s}=+1.7\end{array}$ \\
\hline Belgium & VU & 21913 & -2.9 & -3.4 & $\begin{array}{l}\text { Started center, veered to center left in late } 60 \mathrm{~s} \text {, climbed back center-right and moved } \\
\text { to center } \\
50 \mathrm{~s}=\sim \sim \sim 60 \mathrm{~s}=-5.8 \quad 70 \mathrm{~s}=-8.4 \quad 80 \mathrm{~s}=+4.7 \quad 90 \mathrm{~s}=-2.9\end{array}$ \\
\hline Canada & PC & 62620 & 4.2 & 6.2 & $\begin{array}{l}\text { Center until mid-70s and drifted to right-center thereafter } \\
50 \mathrm{~s}=-2.4 \quad 60 \mathrm{~s}=-0.6 \quad 70 \mathrm{~s}=+2.3 \quad 80 \mathrm{~s}=+14.9\end{array}$ \\
\hline Denmark & $\mathrm{CD}$ & 13330 & 21.9 & 21.3 & $\begin{array}{l}\text { Started right (70s), stay right in } 80 \mathrm{~s} \text { and moved to center in } 90 \mathrm{~s} \\
50 \mathrm{~s}=\sim \sim \sim \mathrm{s}=\mathrm{s}=+26.7 \quad 80 \mathrm{~s}=+25.1 \quad 90 \mathrm{~s}=+6.0\end{array}$ \\
\hline Denmark & $\mathrm{KrF}$ & 13520 & 20.3 & 18.6 & $\begin{array}{l}\text { Started right (70s), moved to center-right in } 80 \mathrm{~s} \text {, and stayed } \\
50 \mathrm{~s}=\sim \sim \sim 70 \mathrm{~s}=+30.0 \quad 80 \mathrm{~s}=+12.2\end{array}$ \\
\hline Ireland & $\mathrm{FF}$ & 53620 & 6.4 & 8.3 & $\begin{array}{l}\text { Started center, moved right in } 60 \mathrm{~s} \text { and } 70 \mathrm{~s} \text {, jumped back to center in late } 70 \mathrm{~s} \text { and } \\
\text { stayed center } \\
\begin{array}{ll}50 \mathrm{~s}=+8.0 \quad 60 \mathrm{~s}=+22.4 \quad 70 \mathrm{~s}=+26.5 \quad 80 \mathrm{~s}=-10.2 \quad 90 \mathrm{~s}=+0.7\end{array}\end{array}$ \\
\hline
\end{tabular}

Netherlands PvdA $22320 \quad-25.0 \quad-25.5 \quad$ Started left (60s), moved steadily left in 60s and 70s, and back toward and to center-left in $80 \mathrm{~s}$ and $90 \mathrm{~s}$

$50 \mathrm{~s}=-21.3 \quad 60 \mathrm{~s}=-27.6 \quad 70 \mathrm{~s}=-43.3 \quad 80 \mathrm{~s}=-22.5 \quad 90 \mathrm{~s}=-8.9$

Netherlands D'66 $22330 \quad-18.3 \quad-18.3 \quad$ Started left (60s), moved further left in 70s, and to center-left in 80s and 90s $50 \mathrm{~s}=\sim \sim \sim 60 \mathrm{~s}=-18.3 \quad 70 \mathrm{~s}=-30.8 \quad 80 \mathrm{~s}=-11.7 \quad 90 \mathrm{~s}=-13.0$

N.Z. $\quad$ LAB $64320 \quad-24.4 \quad-24.5 \quad$ Started left, moved steadily toward center in $60 \mathrm{~s}$ and $70 \mathrm{~s}$, drifted unsteadily back to left in mid-80s and $90 \mathrm{~s}$

$50 \mathrm{~s}=-34.6 \quad 60 \mathrm{~s}=-29.4 \quad 70 \mathrm{~s}=-16.4 \quad 80 \mathrm{~s}=-11.2 \quad 90 \mathrm{~s}=-22.2$

Norway $\quad$ KF $\quad 12520 \quad 0.1 \quad-2.4 \quad$ Started center-right, drifted steadily to center-left till 90 s, and jumped back to center $50 \mathrm{~s}=+15.7 \quad 60 \mathrm{~s}=-4.5 \quad 70 \mathrm{~s}=-5.2 \quad 80 \mathrm{~s}=-13.8 \quad 90 \mathrm{~s}=+2.0$

Norway $\quad$ Høyre $12620 \quad 4.2 \quad 3.2$ Started center-right, drifted steadily toward center-left from 60 till mid-70s, and moved back to center-right

$50 \mathrm{~s}=+16.4 \quad 60 \mathrm{~s}=0.0 \quad 70 \mathrm{~s}=-14.2 \quad 80 \mathrm{~s}=-2.3 \quad 90 \mathrm{~s}=+14.4$

Sweden SDP $11320 \quad-23.2 \quad-20.6$ Started left, moving a little further left in 60s, jumped to center-left in early 70s, drifted back left, only to move to center in $90 \mathrm{~s}$

$50 \mathrm{~s}=-32.7 \quad 60 \mathrm{~s}=-46.0 \quad 70 \mathrm{~s}=-18.9 \quad 80 \mathrm{~s}=-21.2 \quad 90 \mathrm{~s}=+4.7$

$11420-4.2-6.4$ Started center-right, jumped to left in 60s, and gradually drifted back to center-right $50 \mathrm{~s}=+10.8 \quad 60 \mathrm{~s}=-33.4 \quad 70 \mathrm{~s}=-15.6 \quad 80 \mathrm{~s}=+3.3 \quad 90 \mathrm{~s}=+12.5$

Sweden $\quad$ MSP $\quad 11620 \quad 36.9 \quad 34.9$ Started right, moved to center-right in 70s, moved back to right

$50 \mathrm{~s}=+51.8 \quad 60 \mathrm{~s}=+40.3 \quad 70 \mathrm{~s}=+14.0 \quad 80 \mathrm{~s}=+40.5 \quad 90 \mathrm{~s}=+40.5$

Sweden $\quad$ CP $\quad 11810 \quad-3.3 \quad-0.7 \quad$ Started center drifting right, swung center-left in 60s and stayed until early 80s, drifted to center-right

$50 \mathrm{~s}=+2.5 \quad 60 \mathrm{~s}=-6.5 \quad 70 \mathrm{~s}=-16.2 \quad 80 \mathrm{~s}=-6.8 \quad 90 \mathrm{~s}=+12.9$

Switzerland CVP $43520 \quad 6.6 \quad$ Started right, jumped to center in mid 60s and stays center

$50 \mathrm{~s}=+25.1 \quad 60 \mathrm{~s}=+19.9 \quad 70 \mathrm{~s}=+1.2 \quad 80 \mathrm{~s}=+0.6 \quad 90 \mathrm{~s}=-6.8$

U.K. $\quad$ CON $51620 \quad 7.9 \quad 10.5$ Started variably though slightly left, drifted toward center-right through 60 s and 70 s and to right in $80 \mathrm{~s}$ and $90 \mathrm{~s}$

$50 \mathrm{~s}=-8.0 \quad 60 \mathrm{~s}=+0.8 \quad 70 \mathrm{~s}=+11.0 \quad 80 \mathrm{~s}=+29.7 \quad 90 \mathrm{~s}=+26.8$

U.S. $\quad$ REP $\quad 61620 \quad 13.9$

15.9 Started erratically around center, more reliably center in late $60 \mathrm{~s}$ and $70 \mathrm{~s}$, and moved right in 80 s and $90 \mathrm{~s}$

$50 \mathrm{~s}=+7.0 \quad 60 \mathrm{~s}=+4.3 \quad 70 \mathrm{~s}=+3.7 \quad 80 \mathrm{~s}=+28.5 \quad 90 \mathrm{~s}=+27.3$

Source: Estimations and compilations by authors based on CMP data (Budge et al., 2001). A drifting party takes left-right positions in a manner that change predictably from one election to the next but has an estimated long-run left-right position close to its mean left-right position over the postwar period (within \pm 4 points).

Table 1 . The reason many of these appear to be drifters rather than changers is that along the way their movements were erratic enough as not to provide a firm basis for describing them as trends. Among the drifters in Belgium (if we were to add in the combined liberals of the 1950s and 1960s), the Netherlands, Norway, and Sweden, the movements follow a pattern where the 1960s and 1970s show leftward shift followed by rightward shifts during the 1980s and 1990s. Four other parties did not head toward the right side of 
833 the spectrum during the 1980s and 1990s-the Irish 834 FF, Danish CD and KrF, and the Swiss CVP. Fianna 835 Fáil moved rightward in the 1960s and 1970s only to 836 move leftward toward the center in the 1980s and 837 1990s. The two Danish parties, CD and KrF, started 838 on the right, both having won seats for the first time 839 in the traumatic 1973 election and tended to move 840 slightly leftward toward a center-right position thereaf841 ter. The Swiss CVP appears to have moved erratically 842 but decidedly to the left over the entire period.

The modal outcome is that of the homeostatic wanderers. There are 54 of them, $66.7 \%$ of all the parties analyzed. These are parties that, as the wandering portion of their label suggests, have moved around without developing patterns of sustained change across time. We say of them, then, that, so far as we can tell from the autoregressive estimations, their movements are as-if random. Of course, the "homeostatic" qualifier in the label indicates that a party's wandering is anchored in a meaningful position, presumably to their leaders as well as to voters.

It is proper to ask whether the wandering is untethered or homeostatic. A set of completely random numbers will have a mean; hence having a mean can hardly be a justification for inferring that these parties have an identifiable ideological home. The inference of homeostasis, therefore, rests on how widely these parties wander away from their respective mean positions. The standard deviations around the mean positions of homeostatic wanderers are actually slightly smaller on average than the standard deviations around the regression lines of the changers and the drifters. Among the $54 \mathrm{ho}$ meostatic wanderers, the average standard deviation is 12.4; for the changers and drifters, the average standard deviation around their regression lines (average $s_{e}$ values) is 13.4. In that sense, the unpredictable variation of the homeostatic wanderers based on their means is slightly less than the unpredictable variation based on the otherwise predictable movements of the changers and drifters. In short, a mean position of a homeostatic wanderer generally characterizes its positions as well as a regression equation characterizes a position of a changer or drifter.

Our evidence indicates that one-third of the 81 parties changed their left-right positions in systematic ways. It also indicates that around our best estimate of a party's position through time there is something on the order of 13 standard deviation units of error. Given the systematic change, it is necessary to try to capture the dynamic aspects of party positioning.

A word of caution is in order. Almost surely all the remaining dynamic variation beyond that which we have labeled systematic should not be thrown on the junk pile, to be labeled noise. Statistical models of cross-temporal attributions of stability, change, and noise require one to have in mind a model of 'true behavioral change' in order to be able to separate noise in the measurements from change in the behavior (Heise, 1969). Typically, the implicit model of "true" behavior change is a Markovian process. This is the model implicit in the interpretations we put to our autoregressive equations. In effect, the assumption says that when behavior truly changes it does so systematically (i.e., in predictable ways). It then adds by implication that to the extent behavior is not predictable the remaining portion of the measured signal is noise. A close examination of systematic change by party that we report would reveal at least a few widely accepted real changes that do not show themselves as such in our results. One clear example is Britain's Labour Party. Surely it has moved from left to right under the leadership of Tony Blair and the CMP records that movement. But, because it showed up so late in the CMP series, it effectively is left as noise, because by 1998 it was still too early to say whether the movement was systematic.

\section{Cross-national variation}

We accept that an important purpose of left-right party position indicators is what Castles and Mair have said it is, to provide valid indications of party differences within and across nations. We also accept that party family affiliations are not up to the task of drawing consistent distinctions between parties across nations, even though family affiliations are surely useful for rank orderings within nations (see, for example, the within-nation rank orders from different studies in Mair, 2001: pp. 21-22).

Under the assumption that family affiliation does not travel especially well across nations, we expect that some part of the variation within families comes from national influences on individual parties. Norway's political space, for example, while containing variance that is largely associated with parties from different families, makes its own contribution to the location of Norwegian parties. For that reason, we expect Norway's political parties to be generally to the left of parties that share a nominal family affiliation in, say, Australia and the United States. This is because Norway's labor party (DNA), an affiliate of the social democratic family, is to the left of the social democratic family affiliates of Australian Labour and American Democrats. As well, we expect the Norwegian 
Høyre (conservative family) to be to the left of Australian Liberals and American Republicans (also conservative family affiliates).

Our analyses focus on 79 parties belonging to one of eight families in 17 nations, the same nations used in the factor analysis above (see fn. 1). We include parties from eight families: communists, greens, social democrats, liberals, Christians, agrarians, conservatives, and nationalists. To create a left-right score from the Laver-Hunt data, we follow the recommendation in McDonald and Mendes (2001: p. 99) and calculate a weighted sum of the Laver-Hunt scores on their public ownership, tax/spend, and social permissiveness policy dimensions. The CMP scores are based on average left-right scores over the period 1978-96 (except for Italy for which we calculate a CMP mean through the 1992 elections). For convenience, we linearly transformed all four sets of scores so that each one's metric ranges from a minimum of zero $(0=$ extreme left $)$ to a maximum of ten $(10=$ extreme right). In the case of the CMP data, for which possible maximum left and right values are far removed from the observed maximum values, the re-scaling set $-50=0,0=5$, and $+50=10$-i.e., the re-scaled CMP scores equal $[(\mathrm{CMP}+50) / 10]$.

\subsection{Cross-family variation}

We begin by investigating how the four sets of leftright scores line-up by party family. The family averages are shown in Table 3. As one would expect, on average, communists are far left; greens and social democrats are on the left; liberals, agrarians, and Christians are center to center-right; conservatives are on the right; and nationalists are far right. On this general ordering, all four data sets agree.

A more detailed consideration table, however, with attention focused on variability across and within families, shows the CMP data stand distinct from the three sets of expert survey data. Perhaps most noteworthy is more cross-family and less within-family variation in the expert survey sets compared to the CMP. The experts record more homogeneity within families and more distinctiveness between and among families compared to the record from the CMP. A statistical representation of this is apparent from the $R^{2}$ values at the bottom of the table. Sizable proportions of the left-right variation for the expert data are associated with family affiliation; all three exceed 0.8. Given that error variance (simple noise) almost surely constitutes between 5 and 10 percent of the total variance of each set of expert scores, these $R^{2}$ values are probably too high for confidence that the expert survey results are capturing important within-family, cross-national differences. At a minimum this is contrary to the stated purpose of moving beyond family to more finely graded left-right scores. Therefore, at first reading, the expert survey data do not appear to tell us much about left-right party positions beyond what party family affiliations, standing alone, could have told us. That the CMP data are not so strongly associated with party family, having an $R^{2}$ of 0.553 , is therefore potentially good news. Is it? The answer depends on whether the CMP variation not associated with party family is attributable in part to variation from cross-national differences.

\subsection{Cross-national variation}

One way to estimate where in left-right space each nation's party system operates relative to the space of other nations' party systems is to calculate the distance between each party's left-right position and its family mean and then average those distances by nation. ${ }^{8}$ For nations whose parties stand uniformly to the left of their respective family means, the average distance will be negative; for nations whose parties stand uniformly to the right of their respective family means, the average distance will be positive.

Table 4 reports the national averages. For the CMP data, a statistically significant 38 percent of the variation in these party differences is associated with the nations. Among the expert survey sets of scores, the constructed left-right score for Laver-Hunt has the highest percent of variance associated with nations, 32 percent, but with such a large number of dummy variables it falls just short of statistical significance $(F=1.780$, $P=0.055)$. For the Castles-Mair as well as the Huber-Inglehart scores, the variance associated with

\footnotetext{
${ }^{8}$ Analyzing difference-score variables can create inferential complications. They assume that the coefficient on $X$, in a $(Y-X)$ calculation, is 1.0. If it is not, then analyzing the reasons for the differences reflects in part the reasons for the differences themselves and in part the reasons why the coefficient is not 1.0. We have checked to ensure that such complications do not confound our analyses of cross-national differences. In addition to asking how the difference scores relate to nation dummy variables, we created a variable from the party family means and moved it to the right-hand side of the equation. Thereafter we regressed the respective party scores onto the mean party family values (i.e., $Y$-hat from the party family regression) plus the nation dummy variables. That allows us to check whether the coefficient on that variable is equal 1.0. It is very nearly equal to 1.0 for all four sets of party left-right scores-CMP, $Y$-hat slope, $=1.003$ Castles and Mair $=1.010$; Laver and Hunt $=1.009$; and Huber and Inglehart $=0.994$.
} 
Table 3

Average party left-right positions by party family

\begin{tabular}{|c|c|c|c|c|c|}
\hline \multirow[t]{2}{*}{ Party family } & \multirow[t]{2}{*}{$N$} & \multicolumn{4}{|c|}{ Mean (Standard Deviation) } \\
\hline & & Manifesto Project & Castles \& Mair & Laver \& Hunt & Huber \& Inglehart \\
\hline Communist & 8 & $1.83(0.99)$ & $1.70(0.48)$ & $1.77(0.35)$ & $1.86(0.43)$ \\
\hline Social Democrat & 22 & $3.75(1.18)$ & $3.54(0.98)$ & $3.80(1.08)$ & $3.74(0.82)$ \\
\hline Green & 4 & $3.62(1.29)$ & $3.83(0.83)$ & $3.45(0.70)$ & $2.85(0.71)$ \\
\hline Liberal & 13 & $5.35(1.52)$ & $5.84(1.17)$ & $6.10(1.33)$ & $6.01(1.30)$ \\
\hline Agrarian & 5 & $5.16(1.60)$ & $6.10(0.99)$ & $6.19(0.66)$ & $6.39(1.35)$ \\
\hline Christian Democrat & 11 & $5.67(1.08)$ & $6.31(0.70)$ & $6.79(0.49)$ & $6.27(0.99)$ \\
\hline Conservative & 14 & $6.13(1.63)$ & $7.18(0.73)$ & $7.12(0.87)$ & $6.95(0.77)$ \\
\hline Nationalist & 2 & $7.89(1.06)$ & $9.45(0.50)$ & $8.55(0.95)$ & $9.63(0.53)$ \\
\hline All Parties & 79 & $4.70(1.91)$ & $5.09(2.08)$ & $5.23(2.05)$ & $5.12(2.06)$ \\
\hline \multicolumn{6}{|l|}{ Summary Statistics } \\
\hline$R^{2}$ & & 0.553 & 0.832 & 0.844 & 0.812 \\
\hline $\bar{R}^{2}$ & & 0.509 & 0.815 & 0.829 & 0.793 \\
\hline$s_{e}$ & & 1.336 & 0.892 & 0.850 & 0.936 \\
\hline
\end{tabular}

Notes: Table entries are for party families mean left-right locations based on zero-to-ten metrics for all four data sets. Summary statistics come from regressing the party positions onto dummy variables for each of seven families, withholding one family to serve as the baseline category.

the nation dummy variables is clearly not greater than chance.

The findings in Table 3 combined with those in Table 4 suggest that party locations identified by expert surveys, especially Castles-Mair and Huber-Inglehart, correspond so closely to party family affiliation that information about nations does not tell us very much about party positions. This conclusion should not be overdrawn however; it is conditional upon a statistical analysis that considers all nations jointly. When attention is switched to specific nations, one can see common tendencies that have to be taken to mean that not all the expert cross-national differences are just noise. All four data sets, for example, have parties in Canada placed to the left of their family counterparts. Also, the CMP and expert surveys commonly place parties in Australia to the right of their respective families, on average. Given such commonalities, it has to be said that there is some degree of cross-national validity, or at least reliability, in all four studies.

The question is whether the selected common tendencies are generalizable. We can look at the generalizability by correlating the four sets of national positions reported in Table 4. The six correlations are $(N=17)$ :

CMP \& $\mathrm{C}-\mathrm{M}=0.575(P=0.008)$

$\mathrm{CMP} \& \mathrm{~L}-\mathrm{H}=0.703(P=0.001)$

$\mathrm{CMP} \& \mathrm{H}-\mathrm{I}=0.329$ (not significant, $P=0.099$ )

$\mathrm{C}-\mathrm{M} \& \mathrm{~L}-\mathrm{H}=0.427(P=0.049)$

$\mathrm{C}-\mathrm{M} \& \mathrm{H}-\mathrm{I}=0.036($ not significant, $P=0.445)$

L-H \& H-I $=0.742(P<0.001)$
The evidence of generalizable commonalities across the four studies is mixed. The Castles-Mair national spaces share essentially no variance with HuberInglehart ( $r=0.036$; therefore, $\left.r^{2}=0.001\right)$. The CMP and Laver-Hunt country locations along with the Laver-Hunt and Huber-Inglehart locations share something in the vicinity of 50 percent of variance. Inbetween, the CMP and Castles-Mair share about a third of their variation and Castles-Mair and Laver-Hunt share about one-sixth.

Close inspection of the country-specific numbers in Table 2 reveals that the mixed generalizability comes in large part from five nations being located in very different positions in one or another of the data sets. Castles-Mair places Spanish parties substantially to the right in relation to their party families while the other three studies have Spanish parties substantially to the left relative to their party families. Also, Castles-Mair locates the Austrian system near the center while the other three place it considerably to the right. Huber-Inglehart locates Finland's parties on the right; the other three have Finland on the left. Even more surprising, Huber-Inglehart places the United States' Democrats and Republicans to the left of their family counterparts; the other three studies arrive at the more commonly held view that American parties are substantially to the right of family affiliates. Finally, the four studies render a split decision on New Zealand's party system. Castles-Mair and the CMP put New Zealand's party system on the left, relatively speaking, while Laver-Hunt and Huber-Inglehart report that New Zealand's party system is on the right. 
+ MODEL.

Table 4

Average distance, by nation, between party left-right positions and party family means

\begin{tabular}{|c|c|c|c|c|c|}
\hline \multirow[t]{2}{*}{ Country } & \multirow[t]{2}{*}{$N$} & \multicolumn{4}{|c|}{ Average distance (Standard Deviation) } \\
\hline & & Manifesto Project & Castles \& Mair & Laver \& Hunt & Huber \& Inglehart \\
\hline Canada & 3 & $-0.64(1.07)$ & $-0.52(0.17)$ & $-1.20(0.51)$ & $-1.01(0.92)$ \\
\hline Norway & 6 & $-1.38(0.65)$ & $-0.48(0.77)$ & $-0.57(0.52)$ & $-0.31(0.78)$ \\
\hline UK & 3 & $-0.42(1.80)$ & $-0.56(1.02)$ & $-0.39(1.49)$ & $-0.25(0.96)$ \\
\hline Ireland & 4 & $-0.90(0.83)$ & $-0.06(0.58)$ & $-0.34(0.34)$ & $-0.37(0.88)$ \\
\hline Spain & 5 & $-0.61(0.43)$ & $0.59(0.82)$ & $-0.58(0.93)$ & $-0.56(0.61)$ \\
\hline Finland & 7 & $-0.46(1.35)$ & $-0.20(0.45)$ & $-0.06(0.47)$ & $0.58(0.96)$ \\
\hline Germany & 5 & $0.02(0.85)$ & $-0.01(1.04)$ & $-0.13(0.69)$ & $-0.34(0.64)$ \\
\hline France & 6 & $-0.51(0.90)$ & $-0.13(0.70)$ & $-0.08(0.54)$ & $0.11(0.67)$ \\
\hline Sweden & 4 & $0.51(1.49)$ & $-0.21(0.52)$ & $0.05(0.45)$ & $-0.03(0.89)$ \\
\hline Italy & 7 & $0.84(1.15)$ & $-0.13(0.97)$ & $0.17(0.74)$ & $0.12(0.76)$ \\
\hline Belgium & 7 & $0.18(0.82)$ & $0.13(0.97)$ & $0.14(0.87)$ & $-0.23(0.64)$ \\
\hline Netherlands & 4 & $-0.29(1.01)$ & $0.22(1.19)$ & $0.23(0.81)$ & $0.20(0.59)$ \\
\hline New Zealand & 2 & $-0.53(0.25)$ & $-0.46(1.02)$ & $0.67(1.31)$ & $0.82(1.09)$ \\
\hline Austria & 3 & $1.05(0.58)$ & $-0.03(0.86)$ & $0.51(0.72)$ & $0.82(1.50)$ \\
\hline Australia & 4 & $1.33(1.08)$ & $0.83(1.08)$ & $0.42(0.56)$ & $0.18(1.43)$ \\
\hline Denmark & 7 & $0.91(1.88)$ & $0.35(0.98)$ & $0.68(1.01)$ & 0.41 (1.07) \\
\hline U.S. & 2 & $1.25(0.59)$ & $0.44(1.16)$ & $0.72(0.38)$ & $-0.35(0.15)$ \\
\hline \multicolumn{6}{|c|}{ Summary Statistics } \\
\hline$R^{2}$ & & 0.376 & 0.182 & 0.315 & 0.233 \\
\hline $\bar{R}^{2}$ & & 0.216 & -0.029 & 0.138 & 0.035 \\
\hline$s_{e}$ & & 1.129 & 0.863 & 0.753 & 0.877 \\
\hline
\end{tabular}

Notes: Entries are average within-nation differences between a party's location and its respective family mean. Negative/positive values mean that parties within a given nation are on average to the left (negative) or right (positive) of their party family mean. Summary statistics come from regressing the differences onto 16 nation-specific dummy variables, with one nation serving as the baseline. Standard deviations are reported in parentheses. Reporting the standard deviations supplies the greatest flexibility for readers to test hypotheses about individual nations. The homoscedatic standard errors for nation $i$ are equal to $s_{e} / \sqrt{ } n_{i}$, where $s_{e}$ is the standard error of estimate from the regression (reported under summary statistics at the bottom of the table). The standard errors corrected for heteroscedasticity through weighted least squares equal $\left(s / \sqrt{ } n_{i}\right)$, where $s$ is the standard deviation reported in the table. For testing paired comparisons without assuming homoscedasticity, the standard error for any pair of nations, $a$ and $b$, is $\sqrt{ }\left(s_{a} / n_{a}+s_{b} / n_{b}\right)$, where $s_{a}$ is the standard deviation for nation $a$, and $s_{b}$ is the standard deviation for nation $b$. Nations are ordered top to bottom according to the average left-right national position across all four data sets, with left-most nations at the top.

Recalculating the correlations of national spaces across data sets after excluding the five anomalous nations shows the following $(N=12)$.

$$
\begin{aligned}
& \text { CMP \& C-M }=0.706(P=0.005) \\
& \text { CMP \& L-H }=0.753(P=0.003) \\
& \text { CMP \& H-I }=0.597(P=0.021) \\
& \text { C-M \& L-H }=0.794(P=0.001) \\
& \text { C-M \& H-I }=0.635(P=0.013) \\
& \text { L-H \& H-I }=0.926(P<0.001)
\end{aligned}
$$

Under the restricted set of 12 countries all the correlations are statistically significant.

Considering the evidence overall, we conclude there are problems with the cross-national comparability of party spaces but that several of the problems are identifiable and, in part, surmountable. The cross-national variation in party locations identified in expert surveys appears strongly conditioned by party family affiliation, and as a consequence the cross-national variation is muted.

\section{Discussion and conclusion}

Two aspects of our results are especially important. First, party left-right positions change and drift in systematic ways, movements the CMP measurements allow one to observe but expert surveys do not. That makes the CMP generally preferred to expert surveys for analyses involving left-right party positions over an appreciable amount of time. Second, cross-national variation in expert survey left-right party positions is muted; they contain little more than the variation associated with party reputations as ascertained from party-family affiliation. The CMP measurements contain variation attributable to national differences. Parties in Canada and Norway, for example, are relatively more left-leaning within each party family compared to parties in the same family in the U.S. and Australia. Thus, on the cross-national comparability, too, the CMP data are generally preferred to expert survey data. 
What one makes of these findings and what one does about the CMP data being generally preferred depends on the theoretical concern and empirical conditions of a particular investigation. The analyses presented here are not to be seen as a competition from which a winner is declared. It is not so much that one data set is good and the other bad or one is good but the other better. Until a theoretical concern is specified, such claims are standard-less. Rather, one approach to measuring party positions is more and another less consistent with a particular theoretically anchored investigation.

Some theoretical interests reside with the ideological standing of parties with respect to their longstanding core principles. In those cases, expert survey data can be expected to perform well. It is the longstanding core principles, we surmise, that give rise to expert surveys persistently positioning a party in a similar left-right location across time. If experts, on average, across the several experts from each country, are recording the longstanding core principle positions of parties, then investigations of whether a party's ideological position predicts particular policy stands among its adherents - say, for a member of the European Parliament who sits among one of the transnational parliamentary party groupings somewhat detached from the daily twists and turns of domestic political debates or for a member of the mass public who is likely to have a general, not specific, idea of his or her preferred party's position taking-it would be wise to use party locations measured as longstanding core principle as the indicator of a national party's ideological position. For theoretical concerns that involve party and partisan activity closer to home, and in the sometimes strategic maneuvering of electoral politics, taking account of the shorter run dynamics will usually have importance.

As for the muted cross-national variation in expert surveys, its consideration may well highlight the essential nature of the problem faced when measuring left-right positions through this method. The concept of left-right has no secure anchor. Experts are left to determine their own individual frame of reference. Each expert respondent may set his or her reference in accordance with, say, what it means to be centrist in the expert's own nation. But, because being centrist in Norway is more left-leaning than being centrist in the United States, the between-nation distinction is lost to the nation-specific anchors of national experts. That the Castles-Mair and Huber-Inglehart results have more muted cross-national variation than the Laver-Hunt left-right score might be quite revealing in that regard. That is, the Laver-Hunt distinctiveness may be a consequence of having constructed our Laver-Hunt left-right score from a set of anchored policy positions in each of three policy domains, in contrast to asking experts to locate parties along an unanchored left-right line. ${ }^{9}$ We are not suggesting a simple-minded reasoning process for experts when assigning left-right positions, of the sort where an expert is supposed to think, 'well, this is a party in the social democratic family, so I will give it a left-right score of 3.7.' Rather, we suspect, experts must use some sort of anchor to give meaning to the left-right score they assign. A useful candidate for the anchor, we suppose, is the political center of the national party system. While that works well enough for rank orderings within nations (Mair, 2001), it leaves unanchored a center position that would make measurements across nations comparable.

What can be done? Where either cross-temporal or cross-national comparability is important, interest focuses on left-right, and party positions over the past half-century are critical, the CMP data are preferred to the expert survey data. ${ }^{10}$ On questions related to party positions in specific policy domains-taxes versus spending, privatization, the environment, the European Union, decentralized institutional arrangements, among others-expert surveys have anchors; so, at least for cross-national and very likely for cross-temporal comparisons, survey results may serve quite nicely. And, looking ahead, expert surveys might be able to create anchors by identifying for respondents a common reference-e.g., by saying to the expert respondents something like, 'assuming the American Democrats are at 4.0 on a ten-point left-right scale, where are the parties in your nation located?'

\section{Uncited references}

Bara and Budge, 2001; Budge, 1994

\section{References}

Adams, J., 2001. A theory of spatial competition with biased voters: party policies viewed temporally and comparatively. British Journal of Political Science 31, 121-158.

\footnotetext{
${ }^{9}$ We owe this observation to Michael Laver and much of the commentary that follows to Michael Laver, Simon Hix, and Gary Marks. ${ }^{10}$ It is also possible that computerized coding of party texts, manifestos and other documents, will be developed and analyzed so as to provide confidence in cross-temporal and cross-national comparability of their resulting scores (Kleinnijenhuis and Pennings, 2001; Pennings, 2002; Pennings and Keman, 2002; Laver et al., 2003).
} 
Bara, J., Budge, I., 2001. Party policy and ideology: still new Labour? In: Norris, P. (Ed.), Britain Votes 2001. Oxford University Press, Oxford.

Budge, I., 1994. A new theory of party competition: uncertainty, ideology, and policy equilibria viewed comparatively and temporally. British Journal of Political Science 24, 443-467.

Budge, I., Klingemann, H.-D., Volkens, A., Tannenbaum, E., Bara, J., 2001. Mapping Policy Preferences: Estimates for Parties, Electors, and Governments 1945-1998. Oxford University Press, Oxford.

Castles, F., Mair, P., 1984. Left-right political scales: some 'expert' judgements. European Journal of Political Science 12, 73-88.

Dahl, R.A., 1956. A Preface to Democratic Theory. University of Chicago Press, Chicago.

Downs, A., 1957. An Economic Theory of Democracy. Harper \& Row, New York.

Epstein, L.D., 1964. Electoral decision and policy mandate: an empirical example. Public Opinion Quarterly 28, 564-572.

Erikson, R.S., Michael, B., MacKuen, M.B., Stimson, J.A., 2002. The Macro Polity. Cambridge University Press, New York.

Heise, D.R., 1969. Separating reliability and stability in test-retest correlation. American Sociological Review 34, 93-101.

Huber, J.D., Inglehart, R., 1995. Expert interpretations of party space and party locations in 42 societies. Party Politics 1, 73-111.

Kleinnijenhuis, J., Pennings, P., 2001. Measurement of party positions on the basis of party programmes, media coverage, and voter perceptions. In: Laver, M. (Ed.), Estimating the Policy Position of Political Actors. Routledge, London.

Klingemann, H.-D., Hofferbert, R.I., Budge, I., et al., 1994. Parties, Policies, and Democracy. Westview, Boulder.

Kollman, K., Miller, J.H., Page, S.E., 1992. Adaptive parties in spatial elections. American Political Science Review 86, 929-937.

Kollman, K., Miller, J.H., Page, S.E., 1998. Political parties and electoral landscapes. British Journal of Political Science 28, 129-158.

Laver, M., Hunt, W.B., 1992. Policy and Party Competition. Routledge, New York.

Laver, M., Benoit, K., Garry, J., 2003. Extracting policy positions from political texts using words as data. American Political Science Review 97, 311-331.

Lijphart, A., 1999. Patterns of Democracy. Yale University Press, New Haven.

Mair, P., 1986. Locating Irish parties on a left-right dimension: an empirical enquiry. Political Studies 34, 456-465.

Mair, P., 2001. Searching for the positions of political actors: a review of approaches and a critical evaluation of expert surveys. In: Laver, M. (Ed.), Estimating the Policy Position of Political Actors. Routledge, London.
Mair, P., Castles, F.G., 1997. Revisiting Expert Judgements. European Journal of Political Science 31, 150-157.

McDonald, M.D., Budge, I., 2005. Elections, Parties, and Democracy: Conferring the Median Mandate. Oxford University Press, Oxford.

McDonald, M.D., Mendes, S.M., 2001. The policy space of party manifestos. In: Laver, M. (Ed.), Estimating the Policy Position of Political Actors. Routledge, London.

McDonald, M.D., Paskeviciute, A., Best, R., Cremona, R., 2004. Out of Equilibrium: a Positive Theory of Parties and Representation. Paper Presented at the 2004 Meeting of the Public Choice Society, Baltimore, MD.

Müller, W.C., 2000. Austria: tight coalitions and stable government. In: Müller, W.C., Strøm, K. (Eds.), Coalition Governments in Western Europe. Oxford University Press, Oxford.

Müller, W.C., Strøm, K. (Eds.), 2000. Coalition Governments in Western Europe. Oxford University Press, Oxford.

Narud, H.M., Strøm, K., 2000. Norway: a fragile coalitional order. In: Müller, W.C., Strøm, K. (Eds.), Coalition Governments in Western Europe. Oxford University Press, Oxford.

Pennings, P., 2002. The dimensionality of the EU policy space: the European Elections of 1999. European Union Politics 3, 59-79.

Pennings, P., Keman, H., 2002. Towards a new methodology of estimating policy positions. Quality and Quantity 36, 55-79.

Price, S., Sanders, D., 1993. Modeling government popularity in postwar Britain: a methodological example. American Journal of Political Science 37, 317-334.

Ordeshook, P.C., 1980. Political disequilibrium and scientific inquiry: a comment on William Riker's "Implications from the disequilibrium of majority rule for the study of institutions". American Political Science Review 74, 447-450.

Riker, W.H., 1980. Implications from the disequilibrium of majority rule for the study of institutions. American Political Science Review 74 (2), 432-446.

Riker, W.H., 1983. Political theory and the art of heresthetics. In: Finifter, A.W. (Ed.), Political Science: the State of the Discipline. American Political Science Association, Washington, D.C.

Riker, W.H., 1986. The Art of Political Manipulation. Yale University Press, New Haven.

Shepsle, K., 1979. Institutional arrangements and equilibrium in multidimensional voting models. American Journal of Political Science 23, 27-59.

Shepsle, K.A., Weingast, B.R., 1982. Institutionalizing majority rule: a social choice theory with policy implications. The American Economic Review 72, 367-371.

Spafford, D., 1971. A note on the 'equilibrium' division of the vote. American Political Science Review 65, 180-183. 